\title{
Adaptação transcultural de um instrumento para avaliar o envolvimento de idosos em atividades prazerosas
}

\author{
Cross-cultural adaptation of an instrument to \\ evaluate older people's involvement in \\ pleasant activities
}

\author{
Adaptación transcultural de un instrumento para \\ evaluar la participación de los ancianos en \\ actividades placenteras
}

1 Universidade Federal de São
Carlos, São Carlos, Brasil.
Correspondência
H. G. Ferreira
Departamento de Psicologia,
Universidade Federal de
São Carlos.
Rod. Washington Luiz Km
235, São Carlos, SP
13565-905, Brasil.
helogf@gmail.com

Abstract

The sense of pleasure that arises from engagement in activities is a fundamental factor for wellbeing in the elderly. Brazil lacks an instrument to evaluate older people's involvement in pleasant activities. An American instrument was located in the international literature (The California Older Person's Pleasant Events Schedule - COPPES), evaluating the frequency with which older people engage in pleasant activities and the degree of pleasure they associate with each activity. This study's main objective was to conduct a cross-cultural adaptation (semantic, conceptual, cultural, idiomatic, operational, and measurement equivalence) to prepare COPPES for use in Brazil. The main results show that: (a) semantic equivalence of the translated versus original version is satisfactory and (b) the items are relevant to the Brazilian cultural context and evaluate the dimensions identified by the original instrument. The new version of COPPES may contribute to actions focused on promoting older Brazilians' wellbeing.

Aged; Depression; Pleasure
Heloisa Gonçalves Ferreira 1 Elizabeth Joan Barham 1

\section{Resumo}

O prazer experimentado ao se envolver em atividades é fator fundamental para o bem-estar do idoso. No Brasil não existe ainda um instrumento para avaliar envolvimento de idosos em atividades prazerosas. Foi localizado na literatura internacional um instrumento americano (The California Older Person's Pleasant Events Schedule-COPPES) que avalia a frequência de envolvimento de idosos em atividades prazerosas e o prazer experimentado em cada uma delas. O objetivo principal deste trabalho foi submeter o COPPES às etapas de uma adaptação transcultural (equivalência semântica, conceitual, cultural, idiomática e operacional) para a população brasileira. Os principais resultados mostram: (a) uma equivalência semântica satisfatória entre a versão traduzida e a versão original do instrumento; (b) os itens são pertinentes ao contexto cultural brasileiro e avaliam a dimensão proposta pelo instrumento original. A nova versão do COPPES poderá contribuir para ações focadas na promoção de bem-estar entre idosos brasileiros.

Idoso; Depressão; Prazer 
À medida que a expectativa de vida aumenta, torna-se mais evidente a necessidade de buscar alternativas que promovam um envelhecimento bem-sucedido, com bem-estar psicológico, físico e social. Pesquisadores afirmam que o uso de instrumentos psicométricos válidos para avaliar o envolvimento de idosos em atividades prazerosas é de suma importância para intervenções que visam promover o bem-estar dessa população. Não foram localizados na literatura instrumentos brasileiros que avaliam o envolvimento de idosos em atividades prazerosas 1 .

The California Older Person's Pleasant Events Schedule (COPPES) 2 é um instrumento americano composto por 66 itens que avalia a frequência com a qual o idoso esteve envolvido em atividades no último mês, bem como o prazer subjetivo que experimentou ao realizá-las. Após revisão de literatura internacional para localizar instrumentos que mensuram esse construto, o COPPES foi indicado para ser submetido a um processo de adaptação cultural para o Brasil, por aparentar ser o mais adequado ao contexto brasileiro, apresentar boas propriedades psicométricas e considerar a avaliação subjetiva do idoso sobre a prática de atividades prazerosas 1 .

O processo de adaptação transcultural de instrumentos construídos em outros contextos linguísticos e socioculturais é composto pelas etapas de avaliação da equivalência semântica, equivalência conceitual, equivalência cultural, equivalência idiomática, equivalência operacional e equivalência de mensuração 3,4,5.

O presente estudo teve por objetivo submeter o COPPES às seguintes etapas de adaptação transcultural para o Brasil: (1) avaliação da equivalência semântica; (2) avaliação da equivalência conceitual e cultural; (3) avaliação da equivalência idiomática; e (4) avaliação da equivalência operacional. Desta forma, foram realizados um total de quatro estudos para cumprir as etapas referentes ao processo de adaptação transcultural.

\section{Métodos}

\section{Estudo 1: avaliação da equivalência semântica}

\section{- Tradução e consenso das traduções}

O instrumento foi dividido em seis blocos para tradução. Para cada bloco foram realizadas duas traduções: uma por um psicólogo com bons conhecimentos de inglês e outra por um professor de inglês. Cada tradução foi realizada de forma independente, gerando duas versões traduzidas de cada bloco.
O consenso das traduções de cada bloco foi realizado por psicóloga cuja língua nativa era o inglês, com conhecimentos da área de Gerontologia e Psicologia. Após o consenso das traduções, foi gerada a 1ạ versão em português do COPPES (V-1).

\section{- Retro-tradução}

A retro-tradução da V-1 foi realizada de forma independente por uma nativa da língua inglesa com domínio da língua portuguesa e por uma professora de inglês. As duas versões resultantes da retro-tradução foram avaliadas e comparadas com a V-1, pela mesma psicóloga nativa da língua inglesa que realizou o consenso das traduções. Após esta análise, surgiram dúvidas com relação ao significado de alguns itens do instrumento. Estas dúvidas foram encaminhadas aos autores do instrumento original via e-mail. Após resposta dos autores, foram realizados ajustes necessários que originaram a segunda versão em português do COPPES (V-2).

\section{Estudo 2: avaliação da equivalência conceitual e cultural}

Nesta etapa foi verificada correspondência do construto do instrumento original na escala adaptada, bem como adequabilidade dos termos para a cultura brasileira. Para tal, foi constituído Comitê de Especialistas composto por três psicólogas e uma terapeuta ocupacional com experiência de atuação com idosos.

Foi realizada reunião com o Comitê, onde a pesquisadora fez uma breve apresentação sobre a teoria que fundamentou a construção do COPPES. Após a apresentação, os membros receberam formulários para fazer a apreciação da equivalência conceitual e cultural da V-2.

Com base nas sugestões e contribuições dos membros do Comitê, foi produzida a terceira versão em português do COPPES (V-3).

\section{Estudo 3: avaliação da equivalência} idiomática

Participaram desta etapa duas psicólogas com bons conhecimentos de inglês. As participantes receberam um formulário onde deveriam avaliar cada item da V-3 comparando-o ao item do instrumento original, verificando se as expressões da V-3 eram correspondentes ou não correspondentes ao significado denotativo original dos itens da escala original.

Com base nas sugestões e contribuições feitas pelas participantes, foi produzida a quarta versão em português do COPPES (V-4). 


\section{Estudo 4: avaliação da equivalência} operacional

Participaram desta etapa nove idosos não-institucionalizados e sem comprometimento cognitivo, frequentadores de uma unidade do Programa Saúde da Família de um bairro de um município de médio porte do interior de São Paulo.

A V-4 foi aplicada em formato de entrevista. Esta etapa teve como objetivo verificar a aceitabilidade e compreensão da V-4 em uma amostra da população-alvo. Para tal, os participantes responderam a um questionário que avaliava a clareza das instruções de resposta e dos itens desta versão brasileira do COPPES.

Foi solicitado aos participantes que respondessem ao instrumento e que fossem apontadas dúvidas e dificuldades no entendimento dos itens e das instruções do instrumento. Também foram requeridas sugestões que permitissem melhor compreensão do instrumento por parte dos respondentes.

Com base nas informações coletadas, foram efetuados pequenos ajustes na escala chegandose à quinta versão em português do COPPES (V-5).

\section{Aspectos éticos}

Este projeto de pesquisa foi aprovado pelo Comitê de Ética em Pesquisa da Universidade Federal de São Carlos (parecer no 506/2008).

\section{Resultados}

Estudo 1: avaliação da equivalência semântica

Comparando-se a V-1 com a V-2 foram realizadas modificações em alguns itens com base nas retro-traduções e nas respostas dos autores às dúvidas (Tabela 1).

$\mathrm{O}$ item 53 do instrumento original (exploring new areas) foi inicialmente traduzido na V-1 para "visitar novas localidades". Os autores do instrumento original argumentaram que o significado denotativo de "areas" referia-se tanto a lugares geográficos quanto a áreas de conhecimento. Como não foi encontrada uma palavra na língua portuguesa equivalente a "areas" que pudesse expressar adequadamente o significado original do item, optou-se por desmembrar este item em dois: (1) Conhecer sobre novos lugares, e (2) Aprender sobre novos assuntos.

Estudo 2: avaliação da equivalência conceitual e cultural

As modificações realizadas após a verificação da equivalência conceitual e de itens e cultural da $\mathrm{V}-2$ podem ser visualizadas na Tabela 2.

Questionou-se a ocorrência dos itens 34 (" $f a$ zer leituras"), 42 (“ler revistas"), e 46 ("resolver um problema, palavras-cruzadas, jogos de raciocínio"), uma vez que o índice de idosos brasileiros analfabetos é alto. Desta forma, estes itens poderiam não se aplicar a uma parcela da população idosa brasileira. Como alternativa a estes itens, os membros do Comitê sugeriram acrescentar "ver TV/programas na TV/novelas/telejornais/ouvir rádio". Entretanto, para esta primeira fase de adaptação transcultural, deverá ser testada apenas a versão que corresponda às traduções realizadas dos itens da escala original. Além disso, tais atividades não deixam de ser potencialmente agradáveis para idosos que as praticam, mas são praticadas por uma proporção menor de idosos brasileiros (do coorte idoso atual) do que idosos americanos. Essas atividades deveriam ser retiradas ou modificadas na escala apenas se fossem

Tabela 1

Modificações realizadas nos itens da primeira versão brasileira do The California Older Person's Pleasant Events Schedule (COPPES), após as retro-traduções.

\begin{tabular}{|c|c|c|}
\hline Item da versão original & Item da V-1 & Modificação realizada \\
\hline 15. Kissing, touching, showing affection & 15. Fazer carinho, beijar, abraçar, demonstrar afeto & 15. Beijar, abraçar, demonstrar afeto \\
\hline 20. Collecting recipes & 20. Pegar receitas & 20. Colecionar receitas \\
\hline 34. Reading literature & 34. Ler livros & 34. Fazer leituras \\
\hline 46. Solving a problem, puzzle, crossword & $\begin{array}{l}\text { 46. Resolver um problema, palavras-cruzadas ou } \\
\text { montar um quebra-cabeças }\end{array}$ & $\begin{array}{l}\text { 46. Resolver um problema, palavras-cruzadas, jogos de } \\
\text { raciocínio }\end{array}$ \\
\hline 47. Arranging flowers & 47. Arrumar um vaso de flores & 47. Fazer arranjos de flores para enfeitar ambientes \\
\hline 53. Exploring new areas & 53. Visitar novas localidades & $\begin{array}{l}\text { 53. Desmembrar o item em dois: (1) conhecer sobre } \\
\text { novos lugares e ( } 2 \text { ) aprender sobre novos assuntos }\end{array}$ \\
\hline 66. Being near sand, grass, a stream & 66. Estar perto da areia, do mato, de um riacho & 66. Estar perto da natureza (terra, plantas, água) \\
\hline
\end{tabular}


Tabela 2

Modificações realizadas nos itens da segunda versão brasileira do The California Older Person's Pleasant Events Schedule (COPPES), após verificação da equivalência conceitual e de itens e cultural.

\begin{tabular}{|c|c|c|}
\hline Item da versão original & Item da V-2 & Modificação realizada \\
\hline 1. Looking at clouds & 1. Olhar para nuvens & 1. Olhar para o céu \\
\hline $\begin{array}{l}\text { 3. Having people show an interest in what } \\
\text { I say }\end{array}$ & $\begin{array}{l}\text { 3. Pessoas demonstrarem interesse no que } \\
\text { eu digo }\end{array}$ & 3. Pessoas se interessarem pelo que tenho a dizer \\
\hline 4. Thinking about pleasant memories & 4. Pensar em recordações agradáveis & $\begin{array}{l}\text { 4. Pensar em momentos agradáveis do meu } \\
\text { passado }\end{array}$ \\
\hline 7. Having a frank and open conversation & 7. Ter uma conversa sincera e aberta & $\begin{array}{l}\text { 7. Confidenciar abertamente com pessoas de } \\
\text { confiança }\end{array}$ \\
\hline 8. Doing a job well & 8. Fazer bem um trabalho & 8. Fazer bem uma atividade \\
\hline 11. Thinking about myself & 11. Pensar sobre mim mesmo & 11. Pensar em mim \\
\hline 14. Planning trips or vacations & 14. Planejar viagens ou férias & 14. Planejar férias ou viagens \\
\hline 15. Kissing, touching, showing affection & 15. Beijar, abraçar, demonstrar afeto & 15. Abraçar, beijar, demonstrar afeto \\
\hline 17. Meditating & 17. Meditar & 17. Rezar, orar ou meditar \\
\hline 20. Collecting recipes & 20. Colecionar receitas & $\begin{array}{l}\text { 20. Fazer coleções de coisas que me interessam } \\
\text { (receitas, objetos etc.) }\end{array}$ \\
\hline 21. Doing a project my own way & 21. Fazer um projeto à minha maneira & 21. Fazer algo do meu jeito \\
\hline 23. Saying something clearly & 23. Dizer alguma coisa de forma clara & 23. Ser capaz de me comunicar bem \\
\hline $\begin{array}{l}\text { 24. Thinking about something good in the } \\
\text { future }\end{array}$ & 24. Pensar em algo bom para o futuro & $\begin{array}{l}\text { 24. Pensar em algo bom que vai acontecer no } \\
\text { futuro }\end{array}$ \\
\hline 26. Being told I am needed & 26. Ouvir alguém dizer que sou necessário & 26. Ouvir alguém dizer que sou importante \\
\hline 30. Thinking about people I like & 30. Pensar em pessoas que eu gosto & 30. Pensar em pessoas das quais eu gosto \\
\hline 31. Completing a difficult task & 31. Realizar uma tarefa difícil & $\begin{array}{l}\text { 31. Ser bem sucedido após realizar uma tarefa } \\
\text { difícil }\end{array}$ \\
\hline 37. Having peace and quiet & 37. Ter paz e tranqüilidade & 37. Ter momentos de sossego \\
\hline 44. Expressing my love to someone & 44. Expressar o meu amor a alguém & 44. Demonstrar o meu afeto a alguém \\
\hline $\begin{array}{l}\text { 49. Getting out of the city (to the mountains, } \\
\text { seashore, desert) }\end{array}$ & $\begin{array}{l}\text { 49. Sair da cidade (ir para o campo, para a } \\
\text { praia etc.) }\end{array}$ & $\begin{array}{l}\text { 49. Sair da cidade (ir para chácara, sítio, fazenda, } \\
\text { praia etc.) }\end{array}$ \\
\hline 50. Having spare time & 50. Ter tempo livre & 50. Ter um tempo livre \\
\hline 51. Being needed & 51. Me sentir útil & 51. Sentir que sou útil \\
\hline 57. Being loved & 57. Ser amado & 57. Sentir-se amado \\
\hline 58. Visiting a museum & 58. Visitar um museu & $\begin{array}{l}\text { 58. Visitar um museu, uma biblioteca, ou realizar } \\
\text { outra atividade cultural }\end{array}$ \\
\hline 59. Having a daily plan & 59. Ter um dia planejado & 59. Planejar minha rotina diária \\
\hline 61. Listening to classical music & 61. Ouvir música clássica & 61. Ouvir músicas antigas \\
\hline
\end{tabular}

consideradas atividades não-prazerosas, o que provavelmente não seria o caso.

\section{Estudo 3: avaliação da equivalência idiomática}

Após ter sido realizada a apreciação da equivalência idiomática da V-3, foram feitas modificações que produziram a quarta versão em português do COPPES (V-4) (Tabela 3).

Optou-se por suprimir as opções de resposta da segunda pergunta ("Com que frequência este evento ocorreu com você no último mês?”) e subs- tituir tal pergunta por "Quantas vezes este evento ocorreu com você no último mês?”. O participante deveria registrar o número de vezes ao invés de assinalar uma opção de resposta. Optou-se por tais modificações para que o instrumento pudesse captar com mais especificidade, a frequência com que o idoso havia praticado a atividade no último mês.

Nesta etapa, foi acrescentada uma terceira pergunta às instruções de resposta do instrumento ("Numa escala de 0-10, quão prazeroso foi para você este evento?”). Essa alteração foi realizada com o objetivo de acrescentar uma 
Tabela 3

Modificações realizadas nos itens da terceira versão brasileira do The California Older Person's Pleasant Events Schedule (COPPES), após verificação da equivalência idiomática.

\begin{tabular}{|c|c|c|}
\hline Item da versão original & Item da V-3 & Modificação realizada \\
\hline $\begin{array}{l}\text { 3. Having people show an interest in what } \\
\text { I say }\end{array}$ & 3. Pessoas se interessarem pelo que tenho a dizer & $\begin{array}{l}\text { 3. Pessoas demonstrarem interesse no que tenho } \\
\text { a dizer }\end{array}$ \\
\hline 4. Thinking about pleasant memories & $\begin{array}{l}\text { 4. Pensar em momentos agradáveis do meu } \\
\text { passado }\end{array}$ & 4. Pensar em recordações agradáveis \\
\hline 7. Having a frank and open conversation & $\begin{array}{l}\text { 7. Confidenciar abertamente com pessoas de } \\
\text { confiança }\end{array}$ & 7. Ter uma conversa franca e aberta \\
\hline 8. Doing a job well & 8. Fazer bem uma atividade & 8. Fazer bem uma tarefa \\
\hline 20. Collecting recipes & $\begin{array}{l}\text { 20. Fazer coleções de coisas que me interessam } \\
\text { (receitas, objetos etc.) }\end{array}$ & 20. Colecionar receitas \\
\hline 21. Doing a project my own way & 21. Fazer algo do meu jeito & 21. Realizar um plano ou projeto do meu jeito \\
\hline 23. Saying something clearly & 23. Ser capaz de me comunicar bem & 23. Dizer algo de forma clara \\
\hline 25. Looking at the stars or moon & 25. Olhar as estrelas ou a lua & 25. Olhar para as estrelas ou para a lua \\
\hline 31. Completing a difficult task & $\begin{array}{l}\text { 31. Ser bem-sucedido após realizar uma tarefa } \\
\text { difícil }\end{array}$ & 31. Terminar uma tarefa difícil \\
\hline 33. Baking because I feel creative & 33. Cozinhar para usar minha criatividade & 33. Cozinhar porque me sinto inspirado(a) \\
\hline 36. Having an original idea & 36. Ter uma idéia original & 36- ter uma idéia criativa \\
\hline 39. Making a new friend & 39. Fazer um novo amigo & 39. Fazer uma nova amizade \\
\hline 46. Solving a problem, puzzle, crossword & $\begin{array}{l}\text { 46. Resolver um problema, palavras-cruzadas, } \\
\text { jogos de raciocínio }\end{array}$ & $\begin{array}{l}\text { 46. Solucionar um problema, palavra-cruzada, } \\
\text { jogo de raciocínio }\end{array}$ \\
\hline 47. Arranging flowers & $\begin{array}{l}\text { 47. Fazer arranjos de flores para enfeitar } \\
\text { ambientes }\end{array}$ & 47. Fazer arranjos de flores \\
\hline 48. Helping someone & 48. Ajudar alguém & 48. oferecer ajuda a alguém \\
\hline 51. Being needed & 51. Sentir que sou útil & 51. Sentir que alguém precisa de mim \\
\hline 57. Going to church & 57. Ir à igreja & 57. ir à igreja, ao templo \\
\hline 58. Visiting a museum & $\begin{array}{l}\text { 58. Visitar um museu, uma biblioteca, ou realizar } \\
\text { outra atividade cultural }\end{array}$ & $\begin{array}{l}\text { 58. Visitar um museu, uma biblioteca ou outra } \\
\text { atração cultural }\end{array}$ \\
\hline 60. Being with happy people & 60. Estar com pessoas felizes & 60. Estar com pessoas alegres \\
\hline 61. Listening to classical music & 61. Ouvir músicas antigas & 61. Ouvir música clássica \\
\hline 62. Shopping for a new outfit & 62. Comprar roupa nova & 62. Comprar uma roupa nova \\
\hline
\end{tabular}

terceira escala no instrumento, que pudesse captar com maior especificidade o grau de prazer experimentado pelo respondente. Desta forma, foi incluída uma terceira escala com gradação que variava de 0 a 10, em que o respondente deveria assinalar o valor que correspondesse ao grau de prazer/agradabilidade referente à atividade.

\section{Estudo 4: avaliação da equivalência operacional}

$\mathrm{Na}$ fase de teste da V-4 foram constatadas que as seguintes modificações deveriam ser realizadas: (1) acrescentar um exemplo de como responder ao instrumento nas instruções de resposta, e (2) acrescentar exemplos de atividades as quais se referiam alguns itens (Tabela 4 ).
Foi constatado que os respondentes tinham dificuldades para responder à terceira escala acrescentada na V-4. Os respondentes frequentemente assinalavam 0 ou 10, demonstrando dificuldade em discriminar as variações da escala. Por este motivo, optou-se por retirá-la.

Após esta etapa foi produzida a quinta versão em português do COPPES (V-5).

\section{Conclusão}

Os resultados obtidos nas etapas iniciais de adaptação transcultural do COPPES demonstraram equivalência semântica satisfatória entre a versão traduzida e a versão original do instrumento. A análise do Comitê de Especialistas demons- 
Tabela 4

Modificações realizadas nos itens da quarta versão brasileira do The California Older Person's Pleasant Events Schedule (COPPES), após verificação da equivalência operacional.

\begin{tabular}{|c|c|c|}
\hline Item da versão original & Item da V-4 & Modificação realizada \\
\hline $\begin{array}{l}\text { 3. Having people show an interest in what } \\
\text { I say }\end{array}$ & 3. Pessoas se interessarem pelo que tenho a dizer & $\begin{array}{l}\text { 3. Pessoas demonstrarem interesse no que tenho } \\
\text { a dizer }\end{array}$ \\
\hline 8. Doing a job well & 8. Fazer bem uma tarefa & $\begin{array}{l}\text { 8. Fazer bem uma tarefa (Ex.: cozinhar bem } \\
\text { algum prato, fazer bem algum conserto } \\
\text { doméstico etc.) }\end{array}$ \\
\hline 9. Listening to sounds of nature & 9. Ouvir sons da natureza & $\begin{array}{l}\text { 9. Ouvir sons da natureza (Ex.: canto dos } \\
\text { pássaros, vento, chuva etc.) }\end{array}$ \\
\hline 21. Doing a project my own way & 21. Realizar um plano ou projeto do meu jeito & $\begin{array}{l}\text { 21. Realizar um plano ou projeto do meu jeito } \\
\text { (Ex.: uma viagem, uma atividade que queira } \\
\text { iniciar etc.) }\end{array}$ \\
\hline 32. Amusing people & 32. Divertir pessoas & $\begin{array}{l}\text { 32. Divertir pessoas (Ex.: contar piadas, entreter } \\
\text { alguém com histórias e brincadeiras etc.) }\end{array}$ \\
\hline 36. Having an original idea & 36. Ter uma idéia original & 36. Ter uma idéia criativa \\
\hline 48. Helping someone & 48. Ajudar alguém & 48. Oferecer ajuda a alguém \\
\hline 57. Going to church & 57. Ir à igreja & 57. Ir à igreja, ao templo \\
\hline 65. Planning or organizing something & 65. Planejar ou organizar alguma coisa & $\begin{array}{l}\text { 65. Planejar ou organizar alguma coisa (Ex.: uma } \\
\text { festa, uma reunião, um evento etc.) }\end{array}$ \\
\hline
\end{tabular}

trou que os itens são pertinentes ao contexto cultural brasileiro e avaliam a dimensão proposta pelo instrumento original.

Diante desses resultados, seria possível prosseguir com etapas do processo de validação da versão brasileira do COPPES objetivando investigar evidências de validade interna e externa da escala (avaliação da equivalência de mensuração entre a versão original e brasileira do instrumento) $3,4,5$.

Sobre a validade interna do instrumento, seria importante avaliar a consistência interna, bem como buscar dados sobre a validade fatorial. Sobre a validade externa, o objetivo geral seria avaliar a relação entre os escores obtidos com o instrumento e outros construtos ou comportamentos das pessoas avaliadas, para os quais acredita-se existir uma relação cotemporal ou de causa e efeito.

Espera-se que a versão brasileira do COPPES contribua para o desenvolvimento de estratégias preventivas, focadas na promoção de bem-estar entre os idosos brasileiros. 


\section{Resumen}

El placer experimentado al participar en las actividades es esencial para el bienestar de los ancianos. En Brasil no hay un instrumento para evaluar la participación de los ancianos en actividades placenteras. En la literatura internacional hay un instrumento americano (The California Older Person Pleasant Events COPPES) que evalúa la frecuencia de la participación en actividades placenteras para los ancianos y el placer experimentado en cada una de ellas. El objetivo principal de este trabajo es presentar los pasos de la adaptación transcultural de COPPES (equivalencia semántica, conceptual, cultural, idiomática y operacional) para la población brasileña. Los principales resultados muestran: (a) una equivalencia semántica satisfactoria entre la versión traducida y la versión original del instrumento, (b) los ítems del instrumento son relevantes para el contexto cultural brasileño y evalúan las dimensiones propuestas por el instrumento original. La nueva versión de COPPES puede contribuir a las acciones centradas en la promoción del bienestar de los ancianos brasileños.

Anciano; Depresión; Placer

\section{Colaboradores}

H. G. Ferreira redigiu o artigo. E. J. Barham revisou o artigo.

\section{Agradecimentos}

A pesquisa de mestrado, da qual este artigo foi parte, foi financiada pela FAPESP (processo o 2008/56855-6).

\section{Referências}

1. Ferreira HG, Barham EJ. O envolvimento de idosos em atividades prazerosas: revisão de literatura sobre instrumentos de aferição. Rev Bras Geriatr Gerontol 2011; 14:579-90.

2. Rider K, Gallagher-Thompson D, Thompson L. California Older Person's Pleasant Events Schedule: manual. http://www.stanford.edu/ group/oafc/Ken/Manual2.pdf (acessado em 21/ Ago/2008).

3. Reichenhein ME, Moraes CL. Operacionalização de adaptação transcultural de instrumentos de aferição usados em epidemiologia. Rev Saúde Pública 2007; 41:665-73.
4. Herdman M, Fox-Rushby J, Badia X. "Equivalence" and the translation and adaptation of health-related quality of life questionnaires. Quality of Life Reasearch 1998; 6:237-47.

5. Beaton DE, Bombardier C, Guillemin F, Ferraz MB. Guidelines for the process of cross-cultural adaptation of self-report measures. Spine 2000; 25:3186-91.

Recebido em 03/Set/2012

Versão final reapresentada em 13/Fev/2013 Aprovado em 30/Jul/2013 